\title{
Dissociation of facial attractiveness and distinctiveness processing in congenital prosopagnosia
}

\author{
Claus-Christian Carbon and Thomas Grüter \\ Department of Psychology, University of Bamberg, Bamberg, Germany
}

Martina Grüter

Münster, Germany

\author{
Joachim E. Weber and Andreas Lueschow \\ Department of Neurology, Charité-Universitätsmedizin Berlin, Berlin, \\ Germany
}

\begin{abstract}
According to the influential model of Bruce and Young (1986) socially relevant facial information is processed separately from facial information leading to individual face recognition. In recent years functional imaging has identified a network of distinct occipitotemporal cortex areas for the processing of these two kinds of information. Functionally it is not clear at which processing level the "social" and the "recognition" pathways diverge. The study of subjects with a profound face recognition and learning deficit (congenital prosopagnosia-cPA) promises for a better understanding of this issue. We therefore tested the perception of attractiveness (a cue of prime social importance) and distinctiveness (a facial feature related to recognition) in 14 people with cPA. Although attractiveness ratings were highly consistent with controls, cPA subjects' distinctiveness ratings showed random patterns. This dissociation of normal attractiveness processing and impaired distinctiveness processing in cPA helps to specifies the nature of the impairment in this condition while shedding light on the functional architecture of normal face processing.
\end{abstract}

Keywords: Averageness; Congenital prosopagnosia; Dissociation; Distinctiveness processing; Facial attractiveness; Face recognition.

Please address all correspondence to Claus-Christian Carbon, Chair General Psychology and Methodology, Department of Psychology, University of Bamberg, Markusplatz 3, D-96047 Bamberg, Germany. E-mail: ccc@experimental-psychology.com

This study was supported by a research grant (FNK) of the University of Bamberg to CCC. We thank Melissa Võ and Andrea Lyman for proofreading the manuscript, as well as three anonymous reviewers and Jim Tanaka for inspiring comments and helpful remarks that helped to improve the manuscript. Last but not least, we are very thankful for the great effort and support that our prosopagnosic participants made by taking part in our study.

\footnotetext{
(C) 2010 Psychology Press, an imprint of the Taylor \& Francis Group, an Informa business http://www.psypress.com/viscog

DOI: $10.1080 / 13506280903462471$
} 
A number of studies have demonstrated that facial attractiveness ratings are surprisingly consistent across and within participants. The high amount of shared taste across different individuals (Langlois et al., 2000), generations (Johnson \& Pittenger, 1984), sexual orientations (Teuscher \& Teuscher, 2007), gender (Zebrowitz, 1997), cultures (Perrett, May, \& Yoshikawa, 1994), and ethnicities (Cunningham, Roberts, Wu, Barbee, \& Druen, 1995) suggests a common facial attractiveness assessment mechanism in the human brain. Facial attractiveness judgement may be universal, but it is certainly not uniform.

Several factors have been shown to influence the rating of attractiveness: Certain geometric properties (Bashour, 2006; see for an overview, Hönn \& Göz, 2007), averageness, facial symmetry, sexual dimorphism (see for a metastudy, Rhodes, 2006), complexion, quality of skin, gaze direction (Fink, Grammer, \& Thornhill, 2001; Jones, DeBruine, Little, Conway, \& Feinberg, 2006), and - especially in women - friendly expression, neoteny, and youthfulness (Tatarunaite, Playle, Hood, Shaw, \& Richmond, 2005).

The term "averageness" needs some clarification. An average face is derived from overlaying individual faces of a target sample or a target population. According to the theory of face space (Lewis, 2004; see Valentine, 1991; for a review see Valentine, 2001) faces are stored as vectors in $n$-dimensional representational spaces. Their common initial point is a continuously and individually adjusted average constructed from recently perceived faces.

Attractiveness has also been connected to averageness (Langlois \& Roggman, 1990). Computer generated average faces are more attractive than most natural faces (Rhodes, 2006) but the most average faces are not the most attractive ones (DeBruine, Jones, Unger, Little, \& Feinberg, 2007; Perrett et al., 1998). Of course, the average of Scandinavian faces will be different from the average in Sicily or in Kenya.

Attractiveness, though, is remarkably indifferent to cultural and racial environments. For example, Rhodes and her colleagues (2005) found a blend of Caucasian and Asian faces to be more attractive than a Caucasian or an Asian average face to both Asian and European subjects.

Therefore, a second model proposes that the point of reference could be a kind of hardwired prototypical face in the sense of innate geometric rules built into the processing of attractiveness. From an evolutionary point of view, this may be the superior option, because a preference for local average faces would enhance the danger of inbreeding. A "hardwired" innate ideal of facial attractiveness would ensure that the actual average facial shapes in a certain population would not change too fast, isolating the population from the rest of humanity in the process. The hardwired prototype and the local average face, in fact, would therefore tend to be quite similar all over the world. 
This, in turn, means the models would be difficult to tell apart. In the first model, the attractiveness rating would be tied to the initial point of the face vector system. In persons with an impairment confined to the learning and recognition of familiar, even personally familiar faces (see, for a taxonomy, Carbon, 2008) - a condition called prosopagnosia - a severe reduction of configural (face) processing has been reported (Behrmann \& Avidan, 2005; Carbon, Grüter, Weber, \& Lueschow, 2007). It is conceivable that the vector transformation to determine the location of a given face in face space is to a large amount based on the extraction of configural differences to the stored prototype. Intriguingly, the processing of other facial cues of social importance like emotion, age, and gender is not affected (Humphreys, Avidan, \& Behrmann, 2007) or only mildly/sometimes affected (Behrmann \& Avidan, 2005; Duchaine \& Nakayama, 2005; Kress \& Daum, 2003) in cPA. As distinctiveness, the discernibility of individual faces, probably depends on adequate training of the face vector neural network, we may expect to see a degradation in people with cPA. On the other hand, if cPA is strictly associative, affected people should be able to discern faces at a normal level, because their impairment would be due to the inability to retrieve semantic information ("Faces look quite different to me, but I can never say to whom a certain face may belong").

The term "distinctiveness" is somewhat ambiguous, though. It can mean "standing out in a crowd" (referred to as "traditional" by Wickham \& Morris, 2003) or "deviating from the average face" (called "deviation" by Wickham \& Morris). Wickham and Morris (2003) showed that faces which are more attractive than the mean attractiveness did not correlate with distinctiveness when using the "traditional" definition of distinctiveness, whereas for faces that are less attractive than the mean (unattractive) a negative correlation with distinctiveness was obtained, $R=.12, p=.46, n s$ vs. $R=-.55, p<.01$. In our paper, we use distinctiveness in the "traditional" sense; therefore the term should not be considered a reciprocal of averageness.

In people with cPA, the attractiveness ratings would only be affected if they depend on the undisturbed functioning of the neural network representing the face space. But if attractiveness is assessed on the basis of an innate "reference face", people with cPA may show a perfectly normal performance. To our knowledge, this has never been tested before.

For our study we recruited people with congenital prosopagnosia (cPA) who have a specific deficit in recognizing individual faces (Behrmann \& Avidan, 2005; Duchaine \& Nakayama, 2005) and to whom different faces look confusingly similar (Grüter, Grüter, \& Carbon, 2008). They have a reduced facial imagery (Grüter, Grüter, Bell, \& Carbon, 2009), but show an unimpaired or slightly impaired recognition of facial emotion (Behrmann, Avidan, Marotta, \& Kimchi, 2005; Nunn, Postma, \& Pearson, 2001) and 
other facial properties such as gender, age, or attractiveness (Duchaine \& Nakayama, 2005; Grüter et al., 2008).

\section{METHOD}

\section{Participants}

Fourteen people with congenital prosopagnosia (cPA) $\left(M_{\text {age }}=34.6\right.$; three male), identified by face-specific tests and a semistructured interview described in detail elsewhere (Grüter, 2004; Grüter et al., 2008). All reported significant problems with face recognition in everyday life (e.g., "I am sometimes not able to identify familiar faces - even if these faces belong to my nearest friends or relatives"), and had normal or corrected-to-normal vision (assured by standard vision tests). Their face-specific problems were confirmed through several experimental tests, such as a Thatcher grotesqueness decision task indicating strong impairment in configural face processing (see details of this testing in Carbon et al., 2007), reduced face-specific processing, particularly when processing faces that differ in the spatial relationship of cardinal features (Grüter et al., 2009), a face processing skill directly linked to what we know as "face expertise" (Leder \& Carbon, 2006; Schwaninger, Carbon, \& Leder, 2003). In contrast, we found no impairment in object processing, assessed by a parallel set of houses (Grüter et al., 2009). Furthermore, people with cPA had (or were shown to have) strongly impaired face imagery capabilities (Grüter et al., 2009). As controls, we additionally tested two same-sized groups. The first group (Control1) of 14 controls was age and sex matched to the cPA group $\left(M_{\text {age }}=31.1\right.$; three male); the second group (Control2) consisted of 14 undergraduate students who were matched in age to the models used as face stimuli $\left(M_{\text {age }}=24.4\right.$; three male) to optimize the quality of the controls by ruling out age-specific effects (Anastasi \& Rhodes, 2005; Wiese, Schweinberger, \& Hansen, 2008). The group of cPA and the first control group has already been described in detail elsewhere (Carbon et al., 2007). Table 1 shows detailed information about the major symptoms of the participants with cPA and the results of tests related to face recognition and imagery.

\section{Stimuli and apparatus}

The stimuli consisted of photographs of 22 female faces $\left(M_{\text {age }}=23.4\right)$, each in true colour format with the size of $406 \times 561$ pixels from the DADA face database (Carbon, 2001). We used faces of young women because the attractiveness ratings of male faces are confounded by several factors (Rhodes, 2006), which are difficult to control or assess in an experimental 
TABLE 1

Individual data for several questions which have been found to be indicatory for congenital prosopagnosia (Grüter et al., 2008) plus z-scores for tests of face familiarity, recognition, and imagery comparing cPA and Control 1 scores

\begin{tabular}{|c|c|c|c|c|c|c|c|c|c|c|c|c|c|c|}
\hline & \multicolumn{14}{|c|}{ Prosopagnosic participant } \\
\hline & $M B$ & $M M$ & $M D$ & $H G$ & $H M$ & $S A$ & $R E$ & $M U$ & $S S$ & $W B$ & $A R 1$ & $A R 2$ & $H S$ & $S I$ \\
\hline Recognition problems with personally familiar faces & yes & yes & yes & yes & no & yes & yes & yes & yes & yes & yes & no & yes & yes \\
\hline Recognition problems with famous faces & yes & yes & yes & yes & yes & yes & yes & yes & yes & yes & yes & yes & yes & yes \\
\hline Strong usage of face-neutral features & yes & yes & yes & yes & yes & yes & no & yes & yes & yes & yes & yes & yes & yes \\
\hline High false rate of face recognition & yes & yes & yes & yes & no & yes & yes & yes & yes & no & yes & no & yes & yes \\
\hline Problems with film plots due to undistinguishable actors & yes & yes & yes & yes & no & yes & yes & yes & yes & yes & yes & yes & yes & yes \\
\hline Weak imagery of faces & yes & yes & yes & yes & yes & yes & yes & yes & yes & yes & yes & yes & yes & yes \\
\hline Known face recognition problems in family & yes & yes & yes & yes & yes & yes & yes & yes & no & yes & yes & yes & no & no \\
\hline Face familiarity ( $z$-scores) & -4.2 & 0.0 & -2.4 & -5.2 & -2.1 & -3.5 & -1.7 & -3.1 & -2.8 & -3.5 & -4.5 & -3.5 & -4.5 & -2.4 \\
\hline Face recognition ( $z$-scores) & -3.5 & -0.9 & -1.8 & -4.0 & -1.5 & -2.3 & -2.9 & -2.1 & -2.3 & -2.9 & -3.5 & -2.3 & -3.2 & -2.1 \\
\hline Face imagery ( $z$-scores) & -7.3 & -4.3 & -2.6 & -7.3 & -6.9 & -4.8 & -3.1 & -7.3 & -7.3 & -2.6 & -5.6 & -3.5 & -4.8 & -7.3 \\
\hline Age (years) & 39 & 15 & 35 & 56 & 27 & 60 & 34 & 41 & 24 & 34 & 36 & 31 & 24 & 29 \\
\hline Sex, (M)ale/(F)emale & M & $\mathrm{F}$ & $\mathrm{F}$ & $\mathrm{F}$ & M & $\mathrm{F}$ & $\mathrm{F}$ & $\mathrm{F}$ & $\mathrm{F}$ & $\mathrm{F}$ & M & $\mathrm{F}$ & $\mathrm{F}$ & $\mathrm{F}$ \\
\hline
\end{tabular}


setting. Participants sat $65 \mathrm{~cm}$ away from the presenting eMac with an integrated 17-inch CRT monitor, and images were fitted within a visual angle of $4.5^{\circ} \times 6.2^{\circ}$.

\section{Procedure}

First, participants were asked to rate attractiveness in one block for each of the faces on a 7-point Likert scale, from $1=$ "very unattractive" to $7=$ "very attractive". Then they had to rate distinctiveness ("How easily would the face stand out in a crowd?") in a second block on a 7-point Likert scale, from $1=$ "very indistinctive" to $7=$ "very distinctive". All stimuli were unfamiliar to the participants and were presented in a randomized order within each task realized by PsyScope PPC 1.25 (Cohen, MacWhinney, Flatt, \& Provost, 1993). Each stimulus was presented until the participant pressed an answer button. The whole procedure lasted about 10-15 minutes.

\section{RESULTS AND DISCUSSION}

\section{Attractiveness ratings}

Attractiveness rating means did not differ between the groups (cf. Table 2). The cPA group evaluated attractiveness at a level that highly corresponded with both control groups, two-tailed $t \mathrm{~s}(26)<1.23, p \mathrm{~s}>.23$. Furthermore, we found highly similar rating distributions (Figure 1a), further corroborated by high intercorrelations (Table 3 ) between the attractiveness ratings of all groups, $R \mathrm{~s}>.88, p \mathrm{~s}<.0001, \eta_{\mathrm{p}} \mathrm{s}^{2}>.44$. Above that, all rating consistencies were very high. Internal consistencies were calculated by Cronbach's $\alpha$, a statistic calculated from all pairwise correlations between all items. All Cronbach's $\alpha$ were higher than .87 , a sign for good reliabilities. This means that attractiveness ratings are probably based on the same mechanism for all groups.

TABLE 2

Average ratings and internal consistencies (Cronbach's $\alpha$ ) of attractiveness and distinctiveness for all experimental groups

\begin{tabular}{|c|c|c|c|c|c|c|}
\hline Attractiveness & \multicolumn{2}{|c|}{$c P A$} & \multicolumn{2}{|c|}{ Controll } & \multicolumn{2}{|c|}{ Control2 } \\
\hline Rating $(S D)$ & 3.22 & (1.28) & 3.36 & (1.34) & 3.49 & (1.33) \\
\hline Cronbach's $\alpha$ & & & & & & \\
\hline $\begin{array}{l}\text { Distinctiveness } \\
\text { Rating }(S D) \\
\text { Cronbach's } \alpha\end{array}$ & 2.96 & (1.40) & 4.11 & (1.63) & 3.87 & $(1.54)$ \\
\hline
\end{tabular}





Figure 1. Distribution of ratings given by mean probabilities of selected rating levels (1-7) for (a), the attractiveness task, and (b) the distinctiveness task. For the attractiveness ratings, there was no difference in the quality of ratings between the groups, thus prosopagnosics (cPA: Solid black) were not impaired regarding the evaluation of attractiveness. However, there is a clear dissociation for the distinctiveness task between congenital prosopagnosics and both control groups.

As indicated by the scatterplot shown in Figure 2, attractiveness ratings for each face were similar between the control group (Control1) and the group of cPA. 
TABLE 3

Intercorrelations of all experimental groups for attractiveness and distinctiveness ratings

\begin{tabular}{lccc}
\hline & $c P A$ & Controll & Control2 \\
\hline Attractiveness & & & \\
CPA & 1 & $.90^{*}$ & $.88^{*}$ \\
Control1 & $.90^{*}$ & 1 & $.89^{*}$ \\
Control2 & $.88^{*}$ & $.89^{*}$ & 1 \\
Distinctiveness & & & $.13 \dagger$ \\
CPA & 1 & $.26 \dagger$ & $.89^{*}$ \\
Control1 & $.26 \dagger$ & 1 & 1 \\
Control2 & $.13 \dagger$ & $.89^{*}$ & \\
\hline
\end{tabular}

*indicates significance on $p<.0001 ;$ †indicates nonsignificant correlations.

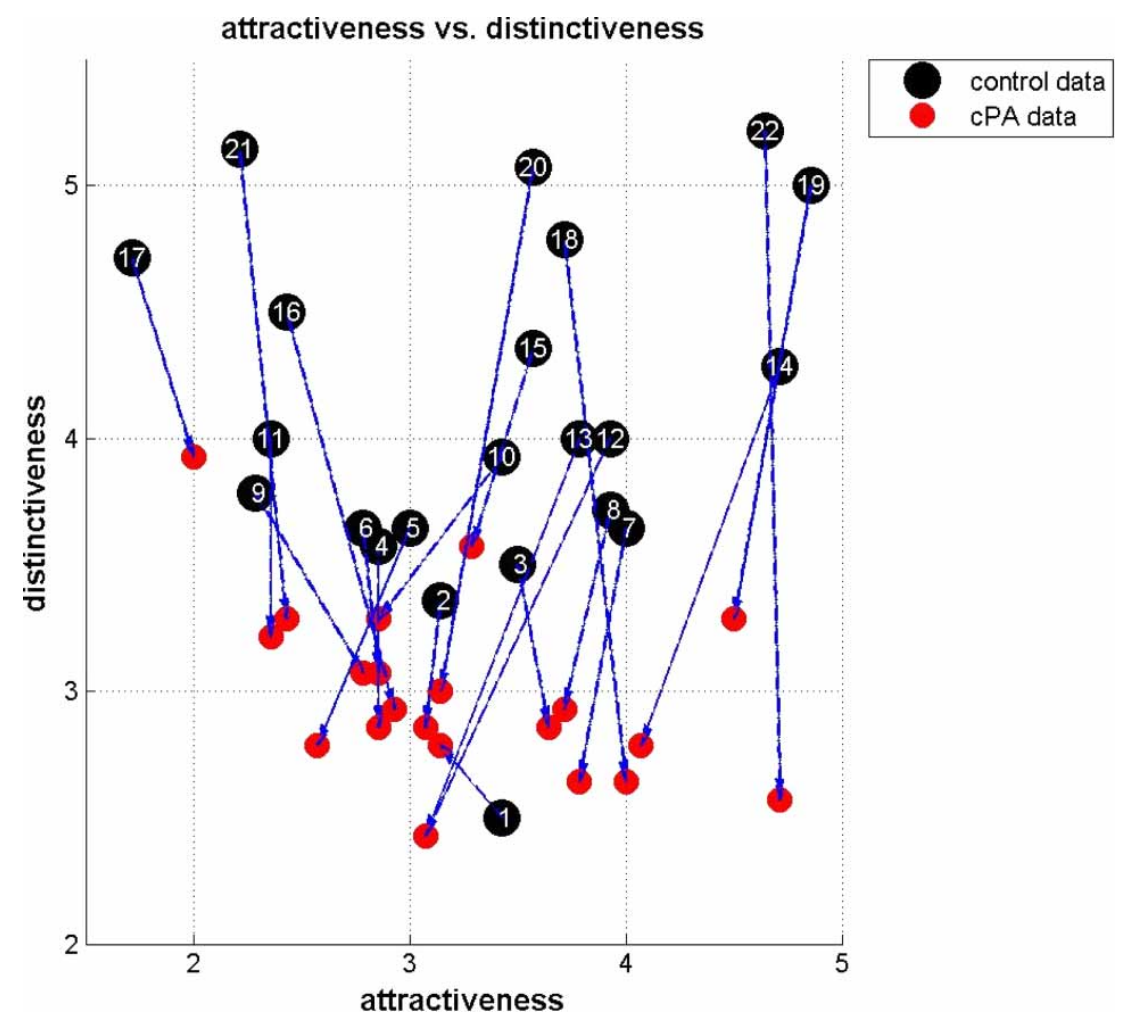

Figure 2. Scatterplot of attractiveness (x-axis) and distinctiveness (y-axis) ratings of all 22 faces for the Controll group (control data: Large black circles) and the group of people with cPA (cPA data: Small red circles). Blue lines connect same faces, indicating strong discrepancies in ratings for distinctiveness but not for attractiveness ratings. To view this figure in colour, please see the online issue of the Journal. 


\section{Distinctiveness ratings}

In contrast to attractiveness ratings, the mean distinctiveness ratings of the cPA group were significantly different from both control groups (Figure 1b). People with cPA evaluated faces as less distinctive than both control groups, two-tailed $t \mathrm{~s}(26)>3.47, p \mathrm{~s}<.0018, \eta s^{2}>.32$. When taking the distribution of distinctiveness ratings into account we found strong positive-skewed response behaviour. Distinctiveness ratings did not differentiate much among the stimuli. As cPA's rating consistency was also very low (Cronbach's $\alpha=.30$ ), it could be argued that prosopagnosics either do not rely on a common processing strategy for evaluating distinctiveness or their judgements includes a strong random component. There was only a weak intercorrelation between cPA and both control groups, $p \mathrm{~s}>.24, n s$, whereas both control groups' distinctiveness data was significantly intercorrelated, $p<.0001, \eta_{\mathrm{p}}^{2}=.44$.

As indicated by the scatterplot in Figure 2, distinctiveness ratings of people with cPA differed strongly for most of the 22 faces, compared to the controls. In fact, the prosopagnosics' overall distribution of distinctiveness ratings resembled randomly distributed data, all very low in values, contrasting clearly with the attractiveness ratings which span the entire scope of possible values. Figure 3 shows the averages of all individuals of the control group (Control1) and the cPA group as a scatterplot, illustrating the normal distribution for attractiveness ratings in contrast to low distinctiveness ratings.

\section{CONCLUSIONS/GENERAL DISCUSSION}

People with cPA judged facial distinctiveness inconsistently and very differently from controls. In contrast, their judgement of facial attractiveness was not altered at all. This dissociate finding suggests different underlying cognitive processes or at least partly independent processing for distinctiveness and attractiveness rating. The evaluation of distinctiveness requires comparisons with a stored representation of an average (prototypical) face (Valentine, 1991). The extraction of configural differences of a real world face in comparison to the prototype might be the major factor to determine its distinctiveness. Configural processing is known to be deficient in people with cPA (Behrmann \& Avidan, 2005; Carbon et al., 2007). Attractiveness ratings of people with cPA, in contrast, did not differ significantly from the controls' ratings. This is compatible with typical reports of people with cPA (Grüter et al., 2009).

How can we be certain that the instruction "how easily would the face stand out in a crowd?" does not trigger the lifelong traumatic experience of 


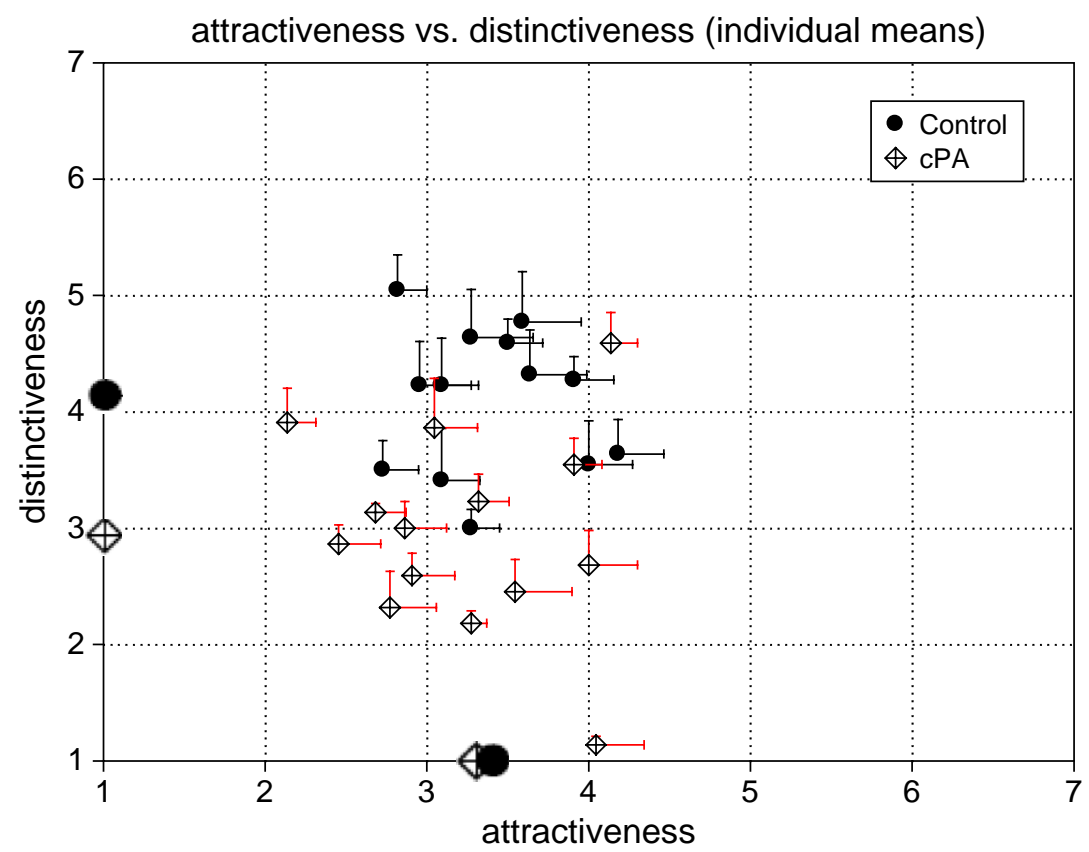

Figure 3. Scatterplot of the mean ratings of attractiveness and distinctiveness for each individual participant (plus grand averages shown directly on the referring axes). The distribution of prosopagnosics' distinctiveness ratings shows a much lower mean, whereas the attractiveness ratings are distributed in a very similar manner among prosopagnosics and controls (Control1). Bidimensional error bars show standard errors of the mean for attractiveness and distinctiveness ratings, respectively. To view this figure in colour, please see the online issue of the Journal.

face recognition failure causing a response bias towards low distinctiveness ratings? In other words, subjects with cPA may not have a deficit per se, but the instruction in the present experiment produces biased results. We do not think that this is valid option, though. Due to their personal histories it became evident to us that the degree of traumatic experience varied considerably between different persons with cPA. The reason can be found in the feedback from the personal environment, which had been incriminating to a different degree. Persons with cPA also reported differently successful compensatory strategies to cope with their deficit. Therefore, a response bias should vary dramatically between subjects with cPA. This should introduce additional and significant variation into this group as compared to controls where such variation is not to be expected. This is not evident from Figure 3, though; here the distribution width is not larger for subjects with cPA.

In general, pattern matching tasks in any neural network tend to produce better discrimination when they are trained with better defined or higher 
contrasted input (Gonzalez \& Woods, 2002). There are indications that, in $\mathrm{cPA}$, the neural network comprising the face space receives insufficient or ill-defined input/feedback, and will therefore produce poor discrimination performance (Thomas et al., 2008). This would introduce a major random component into the process of face vector generation. Any pattern matching in this setting would produce a difference signal with a broad and low amplitude, which would fit well with the answers of the cPA group in the distinctiveness task. This would also explain why people with cPA are not able to generate mental images of faces (Grüter et al., 2009).

If attractive ratings also depend on the face vector system, we would expect inconsistent ratings in the cPA group and low correlations with the control groups. But actually, the internal inconstancies within as well as the intercorrelation between group members were not significantly different for all three groups. This means that, in $\mathrm{CPA}$, facial attractiveness rating is not impaired.

As of yet, only very few imaging studies have studied the neural underpinnings of the processing of attractiveness. The predominant activation of (orbi)frontal structures in a PET study (Nakamura et al., 1998) and two fMRI studies (O'Doherty et al., 2003; Winston, O'Doherty, Kilner, Perrett, \& Dolan, 2007) indicates reward aspects of attractiveness tasks. O'Doherty et al. (2003) found a significant Face gender $\times$ Attractiveness interaction in the anterior ventral bank of the superior temporal sulcus (STS). The authors interpret this finding as being indicative of an STS involvement in social cognition. Indeed, mate selection is a social process in which facial attractiveness is just one component (Greitemeyer, 2007; Maner et al., 2003). The routing of facial attractiveness via the STS could explain why evaluation of this facial attribute functions normally in cPA. This structure, which is assumed to process the social aspects of face recognition (Haxby, Hoffman, \& Gobbini, 2000, 2002), is probably not affected in cPA (Grüter et al., 2008; von Kriegstein et al., 2008); however, within the behavioural approach used in the current work the neural origin of the dissociation can only be a matter of speculation.

The functional model of face processing by Bruce and Young (1986) did not address the processing of attractiveness and distinctiveness in particular, but labelled it overall as "directed visual processing". The dissociation between the evaluation of attractiveness and distinctiveness in subjects with cPA shown here adds two important and new pieces of information to the current debate about normal face processing and about the nature of the cognitive deficit in cPA. In comparison to a standard recognition task that encompasses all the computational steps leading to final recognition success, the distinctiveness task used here does not mandatorily evoke the full range of mnemonic operations such as storage and retrieval of a position in face space to stay with the terminology of the face space model. Therefore, the 
impairment of the of distinctiveness judgement in cPA shows that their face processing is probably already impaired at perceptual stages.

Locating the impairment in cPA to perceptual stages sheds light on the functional architecture of face processing, as the pathways that process attractiveness and distinctiveness obviously diverge already at the perceptual level. Additional behavioural and neurophysiological studies should be carried out to further elucidate the rich and complex interplay of facial subprocesses.

\section{REFERENCES}

Anastasi, J. S., \& Rhodes, M. G. (2005). An own-age bias in face recognition for children and older adults. Psychonomic Bulletin and Review, 12(6), 1043-1047.

Bashour, M. (2006). An objective system for measuring facial attractiveness. Plastic and Reconstructive Surgery, 118(3), 757-774.

Behrmann, M., \& Avidan, G. (2005). Congenital prosopagnosia: Face-blind from birth. Trends in Cognitive Sciences, 9(4), 180-187.

Behrmann, M., Avidan, G., Marotta, J. J., \& Kimchi, R. (2005). Detailed exploration of facerelated processing in congenital prosopagnosia: 1. Behavioral findings. Journal of Cognitive Neuroscience, 17(7), 1-19.

Bruce, V., \& Young, A. (1986). Understanding face recognition. British Journal of Psychology, 77(3), 305-327.

Carbon, C. C. (2001). The DADA faces. A standardized face databank: Faces with different affective states from different angles. Unpublished manuscript, Berlin.

Carbon, C. C. (2008). Famous faces as icons. The illusion of being an expert in the recognition of famous faces. Perception, 37, 801-806.

Carbon, C. C., Grüter, T., Weber, J. E., \& Lueschow, A. (2007). Faces as objects of nonexpertise: Processing of Thatcherised faces in congenital prosopagnosia. Perception, 36(11), $1635-1645$.

Cohen, J. D., MacWhinney, B., Flatt, M., \& Provost, J. (1993). PsyScope: A new graphic interactive environment for designing psychology experiments. Behavioral Research Methods, Instruments, and Computers, 25(2), 257-271.

Cunningham, M. R., Roberts, A. R., Wu, C. H., Barbee, A. P., \& Druen, P. B. (1995). Their ideas of beauty are, on the whole, the same as ours - Consistency and variability in the crosscultural perception of female physical attractiveness. Journal of Personality and Social Psychology, 68(2), 261-279.

DeBruine, L. M., Jones, B. C., Unger, L., Little, A. C., \& Feinberg, D. R. (2007). Dissociating averageness and attractiveness: Attractive faces are not always average. Journal of Experimental Psychology: Human Perception and Performance, 33(6), 1420-1430.

Duchaine, B. C., \& Nakayama, K. (2005). Dissociations of face and object recognition in developmental prosopagnosia. Journal of Cognitive Neuroscience, 17(2), 249-261.

Fink, B., Grammer, K., \& Thornhill, R. (2001). Human (Homo sapiens) facial attractiveness in relation to skin texture and color. Journal of Comparative Psychology, 115(1), 92-99.

Gonzalez, R. C., \& Woods, R. E. (2002). Digital image processing (2nd ed.). Upper Saddle River, NJ: Prentice Hall.

Greitemeyer, T. (2007). What do men and women want in a partner? Are educated partners always more desirable? Journal of Experimental Social Psychology, 43(2), 180-194. 
Grüter, M. (2004). Genetik der kongenitalen Prosopagnosie [Genetics of congenital prosopagnosia]. Unpublished doctoral thesis, Westfälische Wilhelms-Universität Münster, Münster, Germany.

Grüter, T., Grüter, M., Bell, V., \& Carbon, C. C. (2009). Visual mental imagery in congenital prosopagnosia. Neuroscience Letters, 453(3), 135-140.

Grüter, T., Grüter, M., \& Carbon, C. C. (2008). Neural and genetic foundations of face recognition and prosopagnosia. Journal of Neuropsychology, 2(1), 79-97.

Haxby, J. V., Hoffman, E. A., \& Gobbini, M. I. (2000). The distributed human neural system for face perception. Trends in Cognitive Sciences, 4(6), 223-233.

Haxby, J. V., Hoffman, E. A., \& Gobbini, M. I. (2002). Human neural systems for face recognition and social communication. Biological Psychiatry, 51(1), 59-67.

Humphreys, K., Avidan, G., \& Behrmann, M. (2007). A detailed investigation of facial expression processing in congenital prosopagnosia as compared to acquired prosopagnosia. Experimental Brain Research, 176(2), 356-373.

Hönn, M., \& Göz, G. (2007). The ideal of facial beauty: A review. Journal of Orofacial Orthopedics, 68(1), 6-16.

Johnson, D. F., \& Pittenger, J. B. (1984). Attribution, the attractiveness stereotype, and the elderly. Developmental Psychology, 20(6), 1168-1172.

Jones, B. C., DeBruine, L. M., Little, A. C., Conway, C. A., \& Feinberg, D. R. (2006). Integrating gaze direction and expression in preferences for attractive faces. Psychological Science, 17(7), 588-591.

Kress, T., \& Daum, I. (2003). Developmental prosopagnosia: A review. Behavioural Neurology, 14(3-4), 109-121.

Langlois, J. H., Kalakanis, L., Rubenstein, A. J., Larson, A., Hallam, M., \& Smoot, M. (2000). Maxims or myths of beauty? A meta-analytic and theoretical review. Psychological Bulletin, $126(3), 390-423$.

Langlois, J. H., \& Roggman, L. A. (1990). Attractive faces are only average. Psychological Science, 1(2), 115-121.

Leder, H., \& Carbon, C. C. (2006). Face-specific configural processing of relational information. British Journal of Psychology, 97(1), 19-29.

Lewis, M. B. (2004). Face-space-R: Towards a unified account of face recognition. Visual Cognition, 11(1), 29-69.

Maner, J. K., Kenrick, D. T., Becker, D. V., Delton, A. W., Hofer, B., Wilbur, C. J., et al. (2003). Sexually selective cognition: Beauty captures the mind of the beholder. Journal of Personality and Social Psychology, 85(6), 1107-1120.

Nakamura, K., Kawashima, R., Nagumo, S., Ito, K., Sugiura, M., Kato, T., et al. (1998). Neuroanatomical correlates of the assessment of facial attractiveness. Neuroreport, 9(4), 753757.

Nunn, J. A., Postma, P., \& Pearson, R. (2001). Developmental prosopagnosia: Should it be taken at face value? Neurocase, 7(1), 15-27.

O’Doherty, J., Winston, J., Critchley, H., Perrett, D., Burt, D. M., \& Dolan, R. J. (2003). Beauty in a smile: The role of medial orbitofrontal cortex in facial attractiveness. Neuropsychologia, 41(2), 147-155.

Perrett, D. I., Lee, K. J., Penton Voak, I., Rowland, D., Yoshikawa, S., Burt, D. M., et al. (1998). Effects of sexual dimorphism on facial attractiveness. Nature, 394(6696), 884-887.

Perrett, D. I., May, K. A., \& Yoshikawa, S. (1994). Facial shape and judgements of female attractiveness. Nature, 368(6468), 239-242.

Rhodes, G. (2006). The evolutionary psychology of facial beauty. Annual Review of Psychology, 57, 199-226.

Rhodes, G., Lee, K., Palermo, R., Weiss, M., Yoshikawa, S., Clissa, P., et al. (2005). Attractiveness of own-race, other-race, and mixed-race faces. Perception, 34(3), 319-340. 
Schwaninger, A., Carbon, C. C., \& Leder, H. (2003). Expert face processing: Specialization and constraints. In G. Schwarzer \& H. Leder (Eds.), The development of face processing (pp. 8197). Göttingen, Germany: Hogrefe \& Huber Publishers.

Tatarunaite, E., Playle, R., Hood, K., Shaw, W., \& Richmond, S. (2005). Facial attractiveness: A longitudinal study. American Journal of Orthodontics and Dentofacial Orthopedics, 127(6), 676-682.

Teuscher, U., \& Teuscher, C. (2007). Reconsidering the double standard of aging: Effects of gender and sexual orientation on facial attractiveness ratings. Personality and Individual Differences, 42(4), 631-639.

Thomas, C., Avidan, G., Humphreys, K., Jung, K. J., Gao, F., \& Behrmann, M. (2008). Reduced structural connectivity in ventral visual cortex in congenital prosopagnosia. Nature Neuroscience, 12, 29-31.

Valentine, T. (1991). A unified account of the effects of distinctiveness, inversion, and race in face recognition. Quarterly Journal of Experimental Psychology: Human Experimental Psychology, 43A(2), 161-204.

Valentine, T. (2001). Face-space models of face recognition. In M. J. Wenger \& J. T. Townsend (Eds.), Computational, geometric, and process perspectives on facial cognition: Contexts and challenges (pp. 83-113). Hillsdale, NJ: Lawrence Erlbaum Associates, Inc.

Von Kriegstein, K., Dogan, O., Grueter, M., Giraud, A. L., Kell, C. A., Grueter, T., et al. (2008). Simulation of talking faces in the human brain improves auditory speech recognition. Proceedings of the National Academy of Sciences of the USA, 105(18), 6747-6752.

Wickham, L. H. V., \& Morris, P. E. (2003). Attractiveness, distinctiveness, and recognition of faces: Attractive faces can be typical or distinctive but are not better recognized. American Journal of Psychology, 116(3), 455-468.

Wiese, H., Schweinberger, S. R., \& Hansen, K. (2008). The age of the beholder: ERP evidence of an own-age bias in face memory. Neuropsychologia, 46(12), 2973-2985.

Winston, J. S., O’Doherty, J., Kilner, J. M., Perrett, D. I., \& Dolan, R. J. (2007). Brain systems for assessing facial attractiveness. Neuropsychologia, 45(1), 195-206.

Zebrowitz, L. A. (1997). Reading faces: Window to the soul? Boulder, CO: Westview Press.

Manuscript received May 2009 Manuscript accepted October 2009 First published online March 2010 